\title{
Successful revascularization of total occlusion of the left anterior descending artery in a patient with COVID-19 infection and treatment-resistant heart failure
}

\author{
Krystian Gruszka', Piotr Jankowski', Stanisław Bartuś2, Marek Rajzer ${ }^{1}$ \\ ${ }_{1}^{1}$ st Department of Cardiology, Interventional Electrocardiology and Arterial Hypertension, Institute of Cardiology, Jagiellonian University Medical College, Kraków, Poland \\ ${ }^{2} 2^{\text {nd }}$ Department of Cardiology and Cardiovascular Interventions, Institute of Cardiology Jagiellonian University Medical College, Kraków, Poland
}

\author{
Correspondence to: \\ Krystian Gruszka, MD \\ $1^{\text {st }}$ Department of \\ Cardiology, Interventional \\ Electrocardiology and \\ Arterial Hypertension \\ Institute of Cardiology, \\ Jagiellonian University \\ Medical College, \\ Jakubowskiego 2, 30-688 \\ Kraków, Poland, \\ phone: +48 124002100 , \\ e-mail: \\ krystingruszka@gmail.com \\ Copyright by the \\ Author(s), 2021 \\ Kardiol Pol. 2021; \\ 79 (7-8): 889-890; \\ DOI: 10.33963/KP.a2021.0019 \\ Received: \\ January 23, 2021 \\ Revision accepted: \\ May 23, 2021 \\ Published online: \\ May 24, 2021
}

A 56-year-old patient (male, former smoker) was admitted to a municipal hospital due to gradually increasing fatigue, exercise dyspnea, and chest pain persisting for 3 weeks. The new diagnosis of heart failure with reduced ejection fraction (HFrEF) was established, the standard treatment was applied, and the resolution of symptoms was observed. After a few days, a routine test for severe acute respiratory syndrome coronavirus 2 (SARS-CoV-2) was positive. Seven days later, dyspnea and chest pain reappeared. The patient was transferred to the cardiology department dedicated to COVID-19 patients.

On admission to our department, a computer tomography with pulmonary angiogram revealed bilateral, multifocal, ground-glass opacities in the lungs and no signs of pulmonary embolism. Inflammatory markers and $\mathrm{N}$-terminal pro-B-type natriuretic peptide levels were significantly increased, whereas the troponin level was in the normal range. The patient's blood pressure was $86 / 60 \mathrm{~mm}$ $\mathrm{Hg}$, and $\mathrm{SpO}_{2}$ was reduced to $89 \%$. The electrocardiogram showed inverted $\mathrm{T}$ waves in leads V1-V6 without ST-segment depression or elevation. The echocardiography revealed reduced ejection fraction (26\%), severe hypokinesis of the anterior wall, and apical segments (without any features of myocardial necrosis). Viral pneumonia with HFrEF was diagnosed. Mild symptoms of low cardiac output were observed during the first several days of hospitalization. Recurrent episodes of chest pain were also observed over the next few days. Coronary angiography was performed as soon as the circulatory system was stabilized, and the infection was under control [1]. The coronary angiography revealed an occluded left anterior descending artery (LAD) in the proximal segment (Figure 1A). The distal part of the LAD could be seen due to the presence of the collateral circulation from the right coronary artery (Figure 1B) and the circumflex branch. No other significant occlusions of the coronary arteries were observed.

We decided to perform revascularization in this patient due to resistance HFrEF to pharmacotherapy, recurrent chest pain episodes, and likely short LAD occlusion time (about 6 weeks history of chest pain episodes and dyspnea). The heart team recommended percutaneous revascularization which was performed the next day. Right radial access and the antegrade technique were used. The amplatz left guide catheter $6 \mathrm{~F}$ provided adequate support, the LAD occlusion was crossed by guidewire Pilot 50 (Figure 1C), balloon pre-dilatations were performed, and a new drug-eluting stent $(3.5 \times 40 \mathrm{~mm})$ was implanted with a successful final result (Figure 1D). No recurrence of chest pain symptoms and reduction in the severity of heart failure symptoms were observed after this procedure. The patient was discharged as a COVID-19 convalescent.

The rapidly progressing global COVID-19 pandemic presents many difficulties for the functioning of health care systems [2, 3]. Data showed that in Poland the COVID-19 pandemic is associated with a large decline in the performance of invasive cardiology procedures in the setting of the coronary syndrome [4]. Our case report shows that the SARS-CoV-2 infection often coexists with other chronic diseases, which may also be exacerbated. SARS-CoV-2 infection 

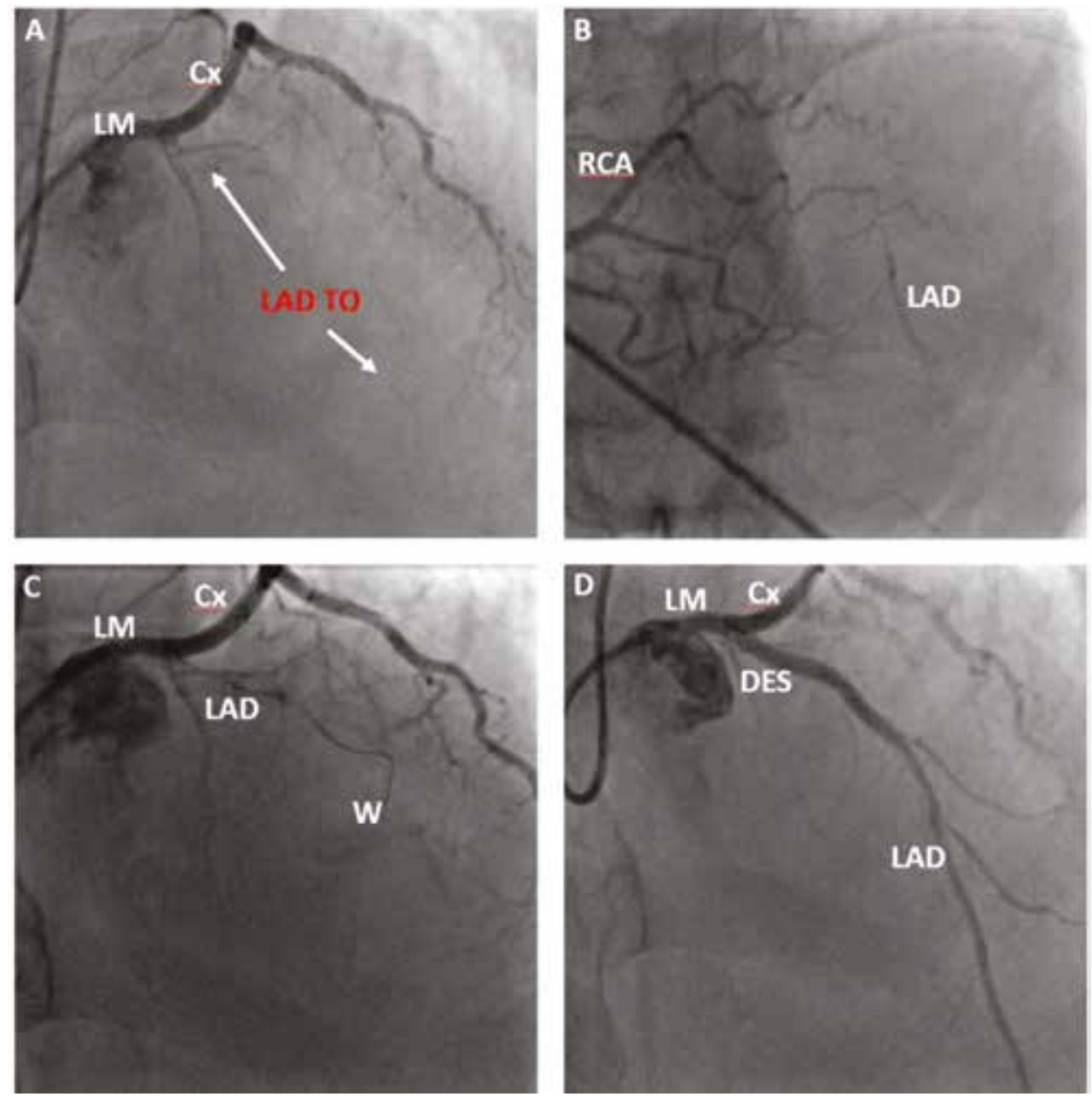

Figure 1. Revascularization of total occlusion of the left anterior descending artery. A. The left coronary artery angiogram. B. The right coronary artery angiogram. C. Antegrade technique revascularization of the total occlusion. D. Final effect of the revascularization

Abbreviations: $C x$, circumflex artery; DES, drug eluting stent in proximal left anterior descending artery; LAD, left anterior descending artery; LAD TO, total occlusion of proximal LAD; LM, left main; RCA, right coronary artery; $W$, coronary guidewire

should not delay treatment of HFrEF and coronary artery disease if the general condition of the patient allows for the required procedures $[1,5]$.

\section{Article information}

Conflict of interest: None declared.

Open access: This article is available in open access under Creative Common Attribution-Non-Commercial-No Derivatives 4.0 International (CC BY-NC-ND 4.0) license, allowing to download articles and share them with others as long as they credit the authors and the publisher, but without permission to change them in any way or use them commercially. For commercial use, please contact the journal office at kardiologiapolska@ptkardio.pl.

How to cite: Gruszka K, Jankowski P, Bartuś S, et al. Successful revascularization of total occlusion of the left anterior descending artery in a patient with COVID-19 infection and treatment-resistant heart failure. Kardiol Pol. 2021; 79(7-8): 889-890, doi: 10.33963/KP.a2021.0019.

\section{REFERENCES}

1. European Society of Cardiology (2020) ESC guidance for the diagnosis and management of CV disease during the COVID-19 pandemic. https:// www.escardio.org/Education/COVID-19-and-Cardiology/ESC-COVID-19Guidance (October 27, 2020).

2. Wu Z, McGoogan JM. Characteristics of and important lessons from the coronavirus disease 2019 (COVID-19) outbreak in China: summary of a report of 72314 cases from the Chinese center for disease control and prevention. JAMA. 2020; 323(13): 1239-1242, doi: 10.1001/jama.2020.2648, indexed in Pubmed: 32091533.

3. Sattar Y, Ullah W, Rauf H, et al. COVID-19 cardiovascular epidemiology, cellular pathogenesis, clinical manifestations and management. Int J Cardiol Heart Vasc. 2020; 29: 100589, doi: 10.1016/j.ijcha.2020.100589, indexed in Pubmed: 32724831.

4. Legutko J, Niewiara $Ł$, Bartuś $S$, et al. Decline in the number of coronary angiography and percutaneous coronary intervention procedures in patients with acute myocardial infarction in Poland during the coronavirus disease 2019 pandemic. Kardiol Pol. 2020; 78(6): 574-576, doi: 10.33963/KP.15393, indexed in Pubmed: 32469190.

5. Flisiak R, Parczewski M, Horban A, et al. Management of SARS-CoV-2 infection: recommendations of the Polish Association of Epidemiologists and Infectiologists. Pol Arch Intern Med. 2020; 130(10): 915-918, doi: 10.20451/pamw.15658, indexed in Pubmed: 33119223. 